\title{
BEHAVIOUR OF SOME IRRADIATED SOLID OXIDES IN DIFFERENT MEDIA AND IN THE PRESENCE OF ADDITIONS
}

\author{
Yerevan State University (YSU), \\ 1, A. Manoogian str., 0025 Yerevan, Armenia \\ norbey@ysu.am
}

Received: February 02, 2009

(c) Ghazarian H., Beylerian N., Baklachev K., 2010

\begin{abstract}
It is known that the properties of filled polymeric glue composites to a great extent depend on the nature and surface properties (SP) of fillers. Usually solid oxides are used as fillers. For the first time the possibility of fillers SP modification exposed to the action of penetrating radiation of small doses $(D)\left(\mathrm{H} \approx 10^{2} \mathrm{~Gy}\right)$ has been shown. The influence of preliminary irradiation (X-rays, gamma) of some mineral powders $\left(\mathrm{SiO}_{2}, \mathrm{MgO}, \mathrm{TiO}_{2}, \mathrm{ZnO}\right.$, talc, kaolin) on their adsorption, suspension, rheologic properties and behaviour in the presence of some additions has been studied. It has been established that oxides SP dependence on irradiation $D$ in absence, as well in the presence of different additions is described by the curves with extremums. They correspond to $D_{e x}$ of the $10^{2} \mathrm{~Gy}$ $\left(10^{4} \mathrm{rads}\right)$ order.
\end{abstract}

Keywords: polymeric glue composites, filler, gammaradiation, X-ray.

\section{Introduction}

It is well known that polymeric materials (PM) are used almost in all fields of human activity. The rapid growth of the modern technologies raises new requests with respect to PM. They concern their mechanical strength, adhesive and dielectric indexes, chemical stability etc. For this reason the production of new PM or their modification are actual problems.

In most cases polymeric composites contain fillers, mainly of inorganic nature. In this case the processes which occur on filler surface play a very important role. It is indispensable to establish their nature and mechanism in order to modify SP in such a way to realize only necessary processes under optimal conditions, indexes, chemical stability and so on. Modification means changes in the structure, i.e. reconstruction of crystalline lattices in the chemical nature of surface layers, e.g. formation of acidbase centers, change of their quantitave ratio.
At the present thermal treatment (in vacuum or in the air) and penetrating radiation $\left(D \approx 10^{5} \mathrm{~Gy}\right)$ are used to modify solids SP. But they have not wide application because the radiation-chemical yields $(Y)$ of modification are low.

Taking into consideration this circumstance we have tried to increase the $\mathrm{Y}$ of solid oxides SP modification using irradiation of extremely small doses $(D=5-500 \mathrm{~Gy})$ with the rate $J=0.5-1 \mathrm{~Gy} / \mathrm{s}$ in the air at room temperatures.

\section{Experimental}

The objects of our studies were: $\mathrm{SiO}_{2}, \mathrm{ZnO}, \mathrm{MgO}$, $\mathrm{Al}_{2} \mathrm{O}_{3}, \mathrm{TiO}_{2}$, talc $\left(\mathrm{MgO} \cdot \mathrm{H}_{2} \mathrm{O} \cdot 4 \mathrm{SiO}_{2}\right)$ and kaolin $\left(\mathrm{MgO} \cdot 2 \mathrm{H}_{2} \mathrm{O} \cdot 4 \mathrm{SiO}_{2}\right)$ which differ by their "prohibited zone width" (from 3 to $10 \mathrm{eV}$ ), specific surfaces $\left(S_{s p}\right)$, surface acid-base properties and ability to undergo phase transitions.

Different methods are used to determine quantitatively the structural and chemical changes which occur in oxides under the irradiation action. All experimental details are presented in [1-6].

Industrial liquid oligomers of epoxy resins (EP) and polyamide hardener (L-20) have been used.

Resin molecular mass $\left(M_{n}\right)$ after adsorption is determined by isopiestic method in the form of $M_{n \text { ads }} / M_{n \text { ini }}$, where $M_{n \text { ini }}$ refers to $M_{n}$ of initial resin [5].

Samples for radiation were prepared using standard vacuum equipment. They were calcined at $420 \mathrm{~K}$ in $\mathrm{O}_{2}$ and rehydrated by water vapour. A part of each sample was used as a control sample.

$\mathrm{Al}_{2} \mathrm{O}_{3}$ sample was obtained by $\mathrm{Al}(\mathrm{OH})_{3}$ calcination with boehmite as a transient phase. $S_{s p}=60 \mathrm{~m}^{2} / \mathrm{g}$ and $d=3.53 \mathrm{~g} / \mathrm{cm}^{3}$. Two samples of $\mathrm{SiO}_{2}$ with $S_{s p}=175$ and $340 \mathrm{~m}^{2} / \mathrm{g}$ were used. Other oxides were industrial samples with $99 \%$ purity.

Adsorbed doses $(D)$ were determined by time exposure. Dosage rate was $0.5-1.0 \mathrm{~Gy} / \mathrm{s}$. 
Calculation of adsorption centers $Y$ was carried out using the relation:

$$
Y=\frac{\Delta \cdot 6 \cdot 10^{23}}{D \cdot 6.25 \cdot 10^{16}} \cdot \frac{1}{100 \mathrm{eV}}
$$

where $\Delta$ is the number of formed adsorption centers $(\mathrm{mol} / \mathrm{kg}) ; Y$ for water and $\mathrm{OH}$-groups was determined analogically according to the data of mass $\operatorname{loss} \alpha(\mathrm{mol} / \mathrm{kg})$ during heating.

To determine adsorption of triethylamine (TEA) and stearic acid (SA), their benzene solutions were used. The adsorbed quantities were determined by titrating and weighing of the residue. Five parallel measurements were made for each case with errors of $\pm 5 \%$. The preliminary irradiated samples were used without any additional treatment [3].

The thermodesorption and dehydration ( $\alpha$ value) were studied using chromatographic method (heating rater $15 \% \mathrm{~min}$, He was a carrier, gas rate was $10 \mathrm{ml} / \mathrm{min}$ ) and derivatographic method. Mass spectral thermodesorption and dehydration analysis were made to register particles with atomic mass 18.

The specific surface $S_{s p}$ was determined by $\mathrm{N}_{2}$ thermal desorption using chromatography [5].

Suspension viscosimetry was investigated using concentric-cylinder viscosimeter [1].

The density was measured using vacuum densimeter $(50 \mathrm{ml})$ in heptane (sample weight was $10 \mathrm{~g}$ ). Weighting and temperature accuracy were $5 \cdot 10^{-4} \mathrm{~g}$ and $0.1^{\circ}$, respectively. The results reproducibility was $\pm 0.1 \%$.

\section{Results and Discussion}

\subsection{The Influence of Irradiation on Solid Oxides at Room Temperatures}

\subsubsection{Radiation modification of $\mathrm{SiO}_{2}$ [7]}

The adsorption (AD) of triethylamine (TEA) and stearic acid (SA), mass losses $(\alpha)$ as the result of dehydration in the temperature range $\Delta T=420-820 \mathrm{~K}(\alpha)$, $\mathrm{OH}$-groups concentration change on oxides surface, density (d) changes as the result of phase transitions are studied.

It has been established that:

(i) The dependence of all cited parameters on $D$ may be expressed by curves which pass through extremum $D_{\text {ex }} \approx 150 \mathrm{~Gy}$.

(ii) Phase transitions occur:

$$
\mathrm{SiO}_{2} \text { (glass)(amorphous) } \frac{\mathrm{D} \leqslant 150 \mathrm{~Gy}}{\overline{\mathrm{D}}>150 \mathrm{~Gy}} \text { (quartz)(cryst) }
$$

It is known that the $d_{\text {cyss }}>d_{\text {amor }}$ [8].

(iii) Preliminary dehydration of $\mathrm{SiO}_{2}$ results in insensibility of surface layers with respect to the irradiation action.

Some data are given in Table 1.
Table 1

Dependence of $\alpha$, TEA Ad and $Y$ on $D ; D=150 \mathrm{~Gy}$

\begin{tabular}{|c|c|c|c|c|}
\hline \multirow{2}{*}{$\mathrm{SiO}_{2}$} & \multicolumn{2}{|c|}{$\mathrm{mol} / \mathrm{kg}$} & \multicolumn{2}{c|}{$10^{-4} . \mathrm{Y}$ for } \\
\cline { 2 - 5 } & $\alpha$ & TEA Ad & $\alpha$ & TEA Ad \\
\hline Initial & 1.00 & 0.27 & - & - \\
\hline Irradiated & 1.40 & 0.71 & 8.1 & 4.4 \\
\hline
\end{tabular}

\subsubsection{Radiation modification of $\mathrm{TiO}_{2}[9]$}

Similar results are obtained. In this case $D_{e x} \cong$ $\cong 300 \mathrm{~Gy}$. TEA Ad has maximum, while SA Ad has a minimum value at $D \cong 300 \mathrm{~Gy}$. So the irradiation results in acidic centers increase in $\mathrm{TiO}_{2}$ superficial layers.

$\mathrm{X}$-ray analysis showed that phase transitions occur:

$$
\text { Rutile } \frac{\mathrm{D}<300 \mathrm{~Gy}}{\mathrm{D}>300 \mathrm{~Gy}} \text { (brookite) }
$$

Such phase transitions occur by heating the sample at $1023 \mathrm{~K}$ [10].

From these data it follows that the phase transition under the influence of irradiation is a reversible process.

For this reason when oxides are treated making use of irradiation great doses $\left(D \geq 10^{5} \mathrm{~Gy}\right)$ or high temperatures phase transitions, SP changes cannot be established as well.

\subsubsection{Radiation modification of $\mathrm{ZnO}$ [11]}

$\mathrm{ZnO}$ contains structural water from 8 to $15 \mu \mathrm{mol} / \mathrm{m}^{2}$ [12]. The removal of physically adsorbed water begins from $340 \mathrm{~K}$ [13]. Noticeable water loss begins from $470 \mathrm{~K}$ [14]. Phase transitions and corresponding cover change of $\mathrm{OH}$-groups are essential processes which occur over $\mathrm{ZnO}$ surface [15].

As the result of prolonged contact of $\mathrm{ZnO}$ with water vapors, $\mathrm{Zn}(\mathrm{OH})_{2}$ is formed and it which under irradiation action loses water. But simultaneously phase transition occurs which acts on SP, particularly on its Ad ability. This process is reversible too. In fact TEA and SA Ad studies show that at $D 300 \mathrm{~Gy}$ TEA Ad has maximum, while SA Ad has a minimum value.

At $D_{\max }$ the radiation-chemical yield $(Y)$, based on TEA Ad alteration, is $4.0 \cdot 10^{2} / 100 \mathrm{eV}$.

\subsubsection{Radiation modification of $\mathrm{Al}_{2} \mathrm{O}_{3}$ [16]}

TEA and SA Ad study on irradiated sample showed an increase of surface acidic centers concentration. This result agrees with literature data concerning diethylamine and pyridine $\mathrm{Ad}$ on thermotreated $\mathrm{Al}(\mathrm{OH})_{3}[17]$. TEA Ad has a maximum value at $D \geq 150 \mathrm{~Gy}$. SAAd has a minimum value at the same $D$ value.

At this $D$ boehmite, as transient and reversible phase, prevails. The irradiation has small effect, if the $\mathrm{Al}_{2} \mathrm{O}_{3}$ sample is preliminary dehydrated by thermotreating at $590 \mathrm{~K}$. 
The increase of $\mathrm{Na}_{2} \mathrm{O}$ content in $\mathrm{Al}_{2} \mathrm{O}_{3}$ results in decreasing radiation modification degree.

\subsubsection{Radiation modification of $\mathrm{MgO}$ [18]}

$\mathrm{MgO}$ has some specific characteristics:

(i) its surface unity contains more constitutional water [19];

(ii) on its surface Lewis acidic centers are absent [20];

(iii) it does not reveal electron-acceptor ability [21].

Irradiated $\mathrm{MgO}$ samples show extremal SP dependence on $D \cong 150 \mathrm{~Gy}$. In this case TEA Ad has a minimum value, while SA has the maximum one. Again reversible radiation induced phase transition occurs at room temperatures:

brucite. $\frac{\mathrm{D} \leqslant 300 \mathrm{~Gy}}{\mathrm{D}>300 \mathrm{~Gy}}$ periclase

Such phase transition may be realized making use of thermal treatment at $670 \mathrm{~K}$ [22]. The radiation-chemical yield is based on weight loss $\alpha$ alteration(dehydration at $470-720 \mathrm{~K}), Y \cong 10^{4} / 100 \mathrm{eV}$.

From the exposed material it follows: subjecting solid oxides to irradiation in the air and at room temperatures with $D$ of the order $10^{2} \mathrm{~Gy}$ becomes possible to modify their SP appreciably. This is very important especially in those cases when the oxides will be used as solid catalysts, dielectric thin film layers, adsorbents, fillers for glue composites.

\subsection{Some Peculiarities of Rheological Properties of Irradiated Oxides Dispersions Obtained in Liquid Medium}

Oxides suspensions have wide applications in obtaining filled PM: varnishes, paints, glues, pasts and so on. The filling efficiency to greater extent depends on the degree of filler $(\mathrm{F})$ dispersion in the given liquid and on its compatibility with the polymer component.
These questions may be easily solved purposefully modifying SP, e.g. irradiating them under the above mentioned conditions.

The modification must favour to change the suspension viscosity $(\eta)$ to the desired side, to enhance the systems aggregate stability which means stability of colloid particles.

Usually one may enhance colloid particles stability covering them with ionic polymers. They cover the particles with layers carrying the same charge. So the coagulation of the colloid may be prevented. As it was shown the irradiation favours to fulfill the cited action.

To verify the plausibility of the expressed proposition the influence of preliminary radiation-induced modification of mineral powders in different mediums and applied $D$ has been studied.

$\mathrm{MgO}, \mathrm{ZnO}, \mathrm{SiO}_{2}, \mathrm{TiO}_{2}, \mathrm{Al}_{2} \mathrm{O}_{3}$, talc and kaolin are used as mineral powders and organic polar (alcohols, esters, ketones, acids) and non polar (hydrocarbons) liquids are used as dispersion media. The applied $D$ is changed in the range 50-1000 Gy.

Suspensions may be characterized by their sedimentation stability. Its quantitative measure is the halftime of destruction (concretion) $\left(t_{t / 2}\right.$ in seconds).

Some obtained data are given in Table 2.

From stated data it follows:

(i) obtained suspensions of irradiated oxides are more stable;

(ii) with the increase of the dispersion medium polarity, suspension stability increases;

(iii) $t_{l / 2}$ dependence on $D$ may be expressed by a bell-shape curve which maximum corresponds to $D_{\max } \approx 10^{2} \mathrm{~Gy}$.

It is also established that suspension $\eta$ obtained on the basis of kaolin in alcohols diminishes according to the following range:

$$
\begin{gathered}
\mathrm{C}_{2} \mathrm{H}_{5} \mathrm{OH}>n-\mathrm{C}_{3} \mathrm{H}_{7} \mathrm{OH}>\text { iso }-\mathrm{C}_{3} \mathrm{H}_{7} \mathrm{OH}>n-\mathrm{C}_{4} \mathrm{H}_{9} \mathrm{OH}> \\
\mathrm{C}_{10} \mathrm{H}_{21} \mathrm{OH}
\end{gathered}
$$

Water results in $\eta$ decrease. Suspension stability increases and $\eta$ decreases when irradiated kaolin samples

Suspensions $t_{1 / 2}$ dependence on $D(J=0.5 \mathrm{~Gy} / \mathrm{s})$

\begin{tabular}{|c|c|c|c|c|c|c|}
\hline \multirow{2}{*}{ Dispersed phase } & \multirow{6}{*}{$\boldsymbol{t}_{1 / 2}$ in seconds at various dozes $D(\mathrm{~Gy})$} \\
\cline { 3 - 7 } & Dispersion medium & $\mathbf{0}$ & $\mathbf{5 0}$ & $\mathbf{8 0}$ & $\mathbf{1 5 0}$ & $\mathbf{2 5 0}$ \\
\cline { 2 - 7 } & & 0 & 17 & 20 & 18 & 12 \\
\cline { 2 - 7 } Kaolin & $\mathrm{CCI}_{4}$ & 10 & 30 & 50 & 30 & 20 \\
\cline { 2 - 7 } & $\mathrm{CH}_{3} \mathrm{COCH}_{3}$ & 150 & 420 & 420 & 420 & 38 \\
\cline { 2 - 7 } & $\mathrm{C}_{2} \mathrm{H}_{5} \mathrm{OH}$ & 90 & 90 & 180 & 180 & 150 \\
\cline { 2 - 7 } & $\mathrm{CH}_{3} \mathrm{COOC}_{2} \mathrm{H}_{5}$ & 52 & 40 & 46 & 37 \\
\hline \multirow{4}{*}{$\mathrm{MgO}$} & $\mathrm{CH}_{3} \mathrm{COCH}_{3}$ & 26 & 780 & 630 & 600 & 560 \\
\cline { 2 - 7 } & $\mathrm{C}_{2} \mathrm{H}_{5} \mathrm{OH}$ & 420 & & & & \\
\end{tabular}


are used. The stated effect may be explained assuming that as the result of irradiation superficial acidic centers concentration is increased. In favor of this conclusion we may state the increase of Tea Ad and the decrease of SA.

It is interesting to note that $\mathrm{SP}$ changes remain for a long time. Study of suspension $\eta$ dependence on $[\mathrm{F}]$ is not examined enough. The study of that question may present the possibility of determining adsorption layers thickness making use of rotation viscosimetry method.

Our experiments showed that suspensions $\eta$ dependence on the content of non-irradiated and irradiated $\mathrm{TiO}_{2}$ in $n-\mathrm{BuOH}$ is very complex (see Fig. 1).

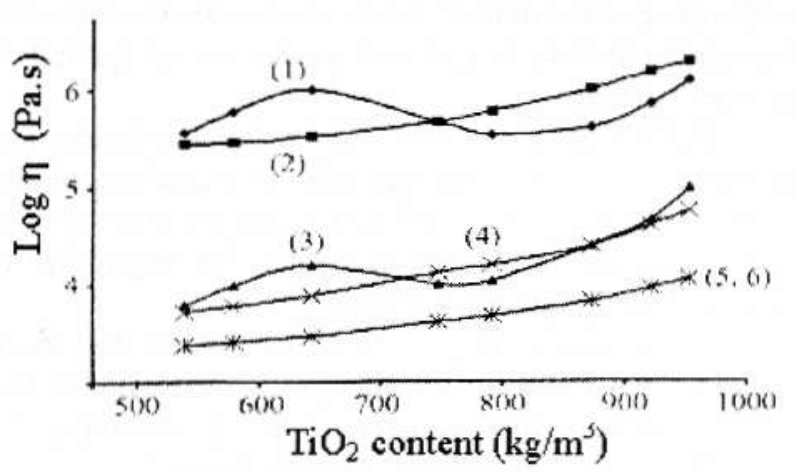

Fig. 1. Dependence of $\eta$ on $\mathrm{TiO}_{2}$ content in $n-\mathrm{BuOH}$ at different rates of shear $\left(g, \mathrm{~s}^{-1}\right)$ using rotation viscosimetry method: $g=8.1(1,2), 1312(3,4), \infty(5,6)$. Curves $(1,3,5)$ relate to irradiated $\mathrm{TiO}_{2}$ samples

(Dopt $=150 \mathrm{~Gy}, J=0.5 \mathrm{~Gy} / \mathrm{s}$, irradiation medium - air) and curves $(2,4,6)$ - to the control samples

In this case $\gamma \rightarrow \infty$ corresponds to $\eta_{\infty}$. It is determined by the formula $\eta=\eta_{\infty}+A \gamma^{-m}$ where $A$ is an empiric constant, $m$ is a parameter which depends on $\mathrm{F}$ dispersity degree.

The peculiarity of irradiated samples behaviour may be explained as follows. When F concentration is relatively low, usually $\eta$ increases with $[\mathrm{F}]$ increase. Beginning from some "critical" concentration "file type" structures are formed in the system as the result of F-medium interactions which result in $\eta$ enhance. Further $[\mathrm{F}]$ increase results in formed "file type" structures are destroyed and the noticed phenomena may not appear (curves 5,6).

We assume that the exposed phenomena are bounded with the system aggregation stability. If this assumption is right then the volume of the precipitate $\left(V_{\mathrm{pr}}\right)$ which may be formed as the result of suspension destructions forces the action between composers particles. To verify the plausibility of this hypothesis $V_{\mathrm{pr}}$ or particle effective radius $(r)$ dependence on the filling degree has been studied. Non-irradiated (control) and irradiated fillers $\left(\mathrm{TiO}_{2}\right)$ are used to obtain suspensions in $n$ - $\mathrm{BuOH}$. Sedimentation analysis is carried out to determine $r$.

Data given in Table 3 show that the suggested hypothesis is probable.
Table 3

Dependence of $r$ of precipitated $\mathrm{TiO}_{2}$ (in $\mathrm{m}$ ) on the filling degree. $D(G y)=150$

\begin{tabular}{|c|c|c|}
\hline \multirow{2}{*}{ Filling degree, $\mathrm{kg} / \mathrm{m}^{3}$} & \multicolumn{2}{|c|}{$10^{6} r$ of precipitated particles } \\
\cline { 2 - 3 } & control & irradiated \\
\hline 10 & 155 & 163 \\
\hline 20 & 160 & 195 \\
\hline 30 & 180 & 226 \\
\hline 40 & 190 & 290 \\
\hline
\end{tabular}

\subsection{Influence of Radiation on Some Properties of Fillers Used in Epoxy Glues}

The surface state of $F$ is one of the most important factors which ensures the receipt of filled PM with performed properties.

From this point of view it is important to know the nature and the strength of intermolecular interactions which occur in the system including heterogeneous processes. The SP modification plays an important role under this treatment which is discussed in detail.

The recipes of epoxy composites, in particular glues, apart binding agents and hardeners also include fillers, accelerants, plasticizers, and so on.

To carry out systematic investigations model systems must be studied at first. To create such systems the number of components must be reduced to minimum.

The results concerning the study of some epoxy glues which contain linking (bonding) compounds ED-20, hardener L-20 and F will be discussed below.

\subsubsection{Interaction of $\mathrm{SiO}_{2}$ with $\mathrm{ED}-20$ and $\mathrm{L}-20$ [23]}

The used $\mathrm{SiO}_{2}$ samples are the same. There are not principal differences in their behaviour. L-20 and ED-20 adsorption dependences on $D$ may the expressed by curves which pass through extremum: maximum in the case of L-20 and minimum in the case of ED-20. In both cases extremum values of Ad correspond to $D_{e x} \cong 150 \mathrm{~Gy}$.

It is obvious that the main acting factor is the nature of the hydrate-hydroxyl cover on $\mathrm{SiO}_{2}$ particles surface. It is shown that concentration changes of both epoxy

and hydroxy $(\mathrm{OH})$ groups occur in systems which consist of mixtures F+ED-20 or F+L-20.

Apart from completion of experiments with cited oligomers it is established, that the mean value of molecular mass $\left(M_{n}\right)$ of the used oligomers in the solution increased. 
This shows that macromolecules with less molecular masses participate mainly in surface reactions, because they are mobile and have more linear structure. To generalize the stated regularities apart from $\mathrm{SiO}_{2}$, other solid oxides as fillers are studied too (see Fig. 2 and Table 4).

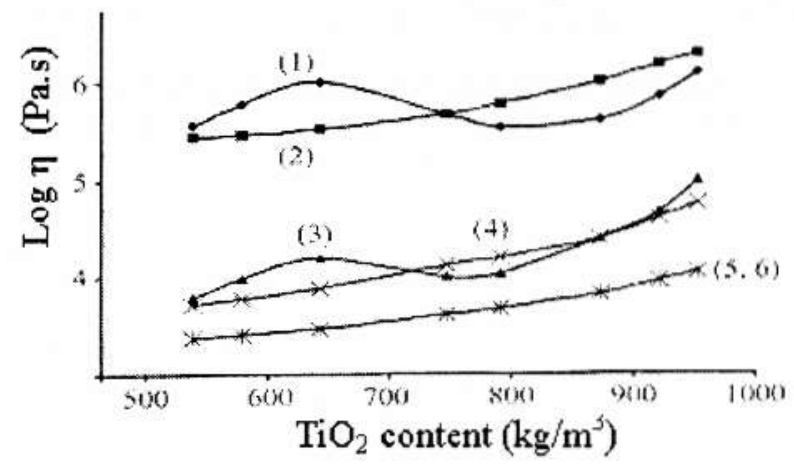

Fig. 2. L-20 adsorption (Ad) dependence on $\mathrm{D}$ on $\mathrm{SiO}_{2}(1)$, $\mathrm{TiO}(2)$ and talc (3)

ED-20 adsorption on $\mathrm{SiO}_{2}$ and $\mathrm{Al}_{2} \mathrm{O}_{3}$ Table 4 (initial ED-20/benzene solution is 7 mas \%, adsorption time is 2 days)

\begin{tabular}{|c|c|c|}
\hline \multirow{2}{*}{$\mathrm{D}, \mathrm{Gy}$} & \multicolumn{2}{|c|}{ Adsorption $10^{3}, \mathrm{~kg} / \mathrm{kg}$} \\
\cline { 2 - 3 } & $\mathrm{SiO}_{2}$ & $\mathrm{Al}_{2} \mathrm{O}_{3}$ \\
\hline Control & 120 & 10.0 \\
\hline 50 & 75 & 7.5 \\
\hline 150 & 60 & 6.6 \\
\hline 150 & 60 & 6.2 \\
\hline 200 & 62 & 7.0 \\
\hline 300 & 70 & 8.0 \\
\hline
\end{tabular}

In the case of $\mathrm{L}-20$ adsorption there is a maximum, while in the case of ED-20 there is a minimum on Ad-D curves. This regularity does not depend on the fillers nature. This circumstance provokes the necessity to pay attention to the sequence of components addition for obtaining glue composite.

From our data it follows that the best glue composite may be obtained when ED-20 is added to the F+L-20 mixture.

The study of the hardening kinetics of prepared glue composite and tensile strength measuring of gluing together proves the rightness of the made conclusion.

\section{Conclusions}

For the first time the possibility of fillers surface properties (SP) modification exposed to the action of penetrating radiation of small doses (D) (approximately of the $100 \mathrm{~Gy}$ order) has been shown. The influence of preliminary irradiation (X-rays, gamma) of some mineral powders $\left(\mathrm{SiO}_{2}, \mathrm{MgO}, \mathrm{TiO}_{2}, \mathrm{ZnO}\right.$, talc, kaolin $)$ on their adsorption, suspensions, rheologic properties and behaviour in the presence of some additions has been studied. It has been established that oxides SP dependence in the absence and in the presence of different additions on irradiation $D$ is described by the curves with extremums. They correspond to $D_{\max }$ of the $100 \mathrm{~Gy}$ (10000 rads) order.

\section{References}

[1] Ghazaryan H., Baklachev E. and Beylerian N.: Zh. Phys. Khimii, 1981, 55, 2432.

[2] Baklachev E., Ghazaryan H. and Beylerian N.: Chem. and Chem. Tech. YSU, 1982, 1, 18.

[3] Ghazaryan H., Grigorian R., Baklachev E. and Beylerian N.: Khim. Vysokyh Energij, 1983, 13, 418.

[4] Baklachev E., Ghazaryan H. and Beylerian N.: Sci. Trans. YSU, 1983, 3, 164.

[5] Baklachev E., Beylerian N. and Ghazaryan H.: Khim. Vysokyh Energij, 1984, 17, 551.

[6] Baklachev E., Ghazaryan H. and Beylerian N.: Arm. Chem. J., 1984, 37, 765 .

[7] Baklachev E., Beylerian N. and Ghazaryan H.: J. Surf. Sci. Techn., 1995, 11, 1.

[8] Komarov V. and Stepanova E.: Izv. Akad. Nauk SRSS, Ser. Khimiya, 1972,4, p.27.

[9] Beylerian N., Baklachev E. and Chazarian H.: J. Surf. Sci. Techn., 1996, 12, p.1.

[10] Goposhenko Ya.: Khimiya titana, Naukova Dumka, Kiev 1970.

[11] Baklachev E., Beylerian N. and Ghazaryan H.: J. Surf. Sci. Techn., 1997, 13, 19.

[12] Chang W., Akhter S. and Kung N.: J. Catalysis, 1983, 82, 341.

[13] Kuminitsu M. and Shigahara K.: Faraday Trans. I, 1980, $76,728$.

[14] Egorov M., Dobropolski N., Kiselev V. et al.: Zh. Phys. Khim., 1965, 39, 3070.

[15] Duek M. and Wilson R.: Faraday Trans. I, 1974, 70, 436.

[16] Baklachev E., Beylerian N. and Ghazaryan H.: J. Surf. Sci. Techn., 1997, 13, 130.

[17] Kirina O., Antinina T. and Shchoukin G.: Zh. Phys. Khim., $1973,47,441$.

[18] Baklachev E., Beylerian N. and Ghazaryan H.: J. Surf. Sci. Techn., 1999, 15, 69.

[19] Marguerite F., Fraissard J. and Imdik B.: Bull. Soc. Chim. France, 1967, 7, 2287.

[20] Tretyakova N. and Fillipov F.: Kinetika i Kataliz, 1970, 11, 989.

[21] Tench A. and Giles D.: Faraday Trans. I, 1972, 68, 193.

[22] Chin D. and Hong P.: J. Therm. Analysis, 1977, 12, 5.

[23] Baklachev E., Beylerian N. and Ghazaryan H.: J. Surf. Sci. Techn., 1997, 13, 11. 


\section{ХАРАКТЕРИСТИКАДЕЯКИХОПРОМІНЕНИХ ТВЕРДИХОКСИДІВ У РІЗНИХ СЕРЕДОВИЩАХІ В ПІРИСУТНОСТІДОДАТКІВ}

Анотацін. Властивості наповнени полімерних клейових композииій значною мірою залежать від природи і поверхневих властивостей наповнювачів, зокрема, твердих оксидів. Вперие показано можсливість модифікаиії поверхневих властивостей твердих оксидів невеликими дозами проникної радіачії $\left.\approx 10^{2} G y\right)$.
Вивчено вплив попереднього опромінювания ( $X$-опромінення, гама-промені) деяких мінераньних пороиків $\left(\mathrm{SiO}_{2}, \mathrm{MgO}, \mathrm{TiO}, \mathrm{ZnO}\right.$. тальк, каолін) на їх адсорбиійні та реологічні властивості $і$ ì поведінку у присутності певних додатків. Встановлена залежиість поверхиевих властивостей оксидів від опромінения у присутності і без додатків, яка має екстремальний характер. Показано, ио максимум відповідає опроміненню порядка $10^{2} \mathrm{~Gy}$.

Ключові слова: полімерні кяейові кояпозиції, наповнювач, гамиа-випромінення, $X$-промені. 